\section{INCREASE OF PRODUCTION PRODUCTIVITY USING THE COMBINED MACHINING IN ONE CLAMPING}

\author{
LADISLAV FUGLICEK \\ Technical university, Faculty of Mechanical Engineering \\ Department of Mechanical Technology \\ Ostrava, Czech Republic \\ DOI: 10.17973/MMSJ.2019_10_2019038 \\ e-mail: ladislav.fuglicek@vsb.cz
}

The Study is focused on machining of complex components in one clamping. Two methods of machining are discussed herein, with conventional machines and a multifunctional machine. The study compares the design solution of both machines as well as elements with potential to improve the efficiency of production. Machining using conventional machines is very timedemanding, not only with regard to the machining, but also preparation and transport times. With multifunctional machines we reduce the time significantly. The study includes an experiment on a selected production component. The result is more efficient production using the multi-functional machine tool and correct selection of the machines for production

KEYWORDS

CNC machine, conventional machine, machining, shaft, production.

\section{INTRODUCTION}

The combination of different machining processes on one machine in one clamping frequently offers savings of machining time. The machining process on conventional machines is very demanding in terms of manual labour and operator's skill. The machine time, precision, quality and meeting deadlines for delivery of components are important for competitiveness. Machining time on conventional machines takes longer than on a modern CNC machine.

Many engineering components require finishing in multiple technological operations, such as e.g. turning, milling, grinding etc. The main requirement is profitable production of single complex components or in small batches. The requirements lead to the integration of several individual machines into a single piece of equipment in a single work space. At present it means multi-functional production machines. Machines, that can turn as well as mill, are predominant. It allows processing very complex geometries of small components with a high degree of precision and production efficiency. [Bilik 1994]

2 ADVANTAGES AND DISADVANTAGES OF EACH METHOD OF MACHINING

At present, CNC machines are used frequently for their great advantages. However, we cannot see them as the ideal solution. Deciding, when to use a conventional machine and when a CNC machines is important.
On a conventional machine the operator plans the production process according to the technological process and technical documentation. The operator assesses the control deviation and reduces it by controlling the machine and the moving parts of the rest, until the component complies with the technical documentation. On a CNC machine the production process is planned before the machining itself. The production process is specified by a CNC program, the tools and clamping are given in the process card, the conditions are given by the programmer - skilled worker. The control deviation is solved by the control unit of the machine through a system of measuring and moving elements. Due to these condition the requirements for the qualification of the workers for machine operation decreases. The production time is precisely specified by the program, independent of the operator, which improves planning and organisation of production.

The shape of the component is another factor of selection of the machine, but it also depends on the production volume. NC machine is more suitable for smaller batches, but repeated production can be considered an advantage for a CNC machine. However, the most important criterion is the economic analysis, which includes the planning and overall possibilities of machining capacities of the company.

When introducing CNC machines it is important to focus on the basic criteria of the machined component, which are key for the selection of the machine type. The criteria include the shape complexity, which, on conventional machines, would require clamping in several fixtures. Other important factors are long preparation times for adjustment and clamping between operations, but also short machine times, small tolerance field of the position of individual design elements or parts with a great number of operations (requiring various machining conditions). [Brychta 2006]

\section{MACHINES FOR COMBINED MACHINING OF SHAFTS}

The decision regarding the machine selection, which will perform the combined machining, always requires the quantification of the real costs and its relationship to the achieved indexes. Thorough analysis, from the economic as well as technical perspective, is also required.

The NC machines frame design is the basis of its conceptional solution, the machine must be light and rigid, with high natural frequencies and good attenuation of mechanical shocks and vibrations, generated during long machining. The frame also includes linear guides or revolving bearing, for which high rigidity and minimal friction at high travel speeds is required. During long machining the "process heat" increases, most of it being disposed together with the chip, so quick removal of chips from the machine's working space is required. Another requirement for the frame is the thermal symmetry and the main sources of heat, which should eliminate the angular deformation and collapse of the frame even with longitudinal expansion.

The NC machine is designed with a very rigid frame for shortest transfer force from the tool to the component, and it must resist torsion forces. Great amount of chips is generated during a long machining. The frame must be designed to allow simple and quick removal of chips from 
the work space of the machine, but also to prevent the possible heating of the machine's frame by the machining chips. [Brychta 2006]

The frame of a conventional machine is robust, but very heavy, which has negative effect on attenuation of vibrations and shocks. The negative characteristics result in wear and tear of the machine and low quality of the surface and dimensions of the machined component. The frames positive characteristics is its dynamic stability and great static rigidity with very short transfer forces, so it resists the torsion forces well. The static rigidity must be sufficient to prevent the deformation from exceeding the permitted values with respect to the product's dimensions. High static rigidity affects also the dynamic performance of the machine. The dynamic stability must ensure the resistance to vibrations, which cause lowquality surface of the product. The frame vibrations reduce the utilisation of the machine's performance and also reduces the rigidity of the frame's joints, which leads to internal tension and subsequent frame deformations. The removal of chips from a conventional machine is problematic. The chips are in the way in the machining position. It also is the source of heat field from the chips, increasing the heating of the frame and the achieved surface of the machined part is of low quality. [Bolek 1989]

The fast integration of turning, drilling, milling and grinding operations leads to creation of high-capacity tool magazines for combined operations. The creation of highcapacity tool magazines is a prerequisite of efficient introduction of such machine. If we focus on unit production or small-batch production, the machine should be highly adaptable for a wide range of products in the segment. The highest flexibility of the machine during production will be achieved by fitting it with such high-capacity tool magazine. The possibility of quick changes of products with the integration of machining operation leads to the increase of the number of checking operation of process measurement and control. This measurement can be performed using measuring probes, which, after clamping of the machined component, will automatically detect the longitudinal and circumferential orientation of the component. The operation is performed to the actual position and eventual detrimental influences are compensated. After the completion of individual operation automatic measurement of the clamped component and recording of final precision of the machined part is possible [Kocman 2001]

Conventional machines have a limited number of tools in the clamping head. Therefore this method leads to increased handling of tools and its replacement in the clamping head, also the handling time for adjustment of the tools increases. The delays reduce the accumulated heat, generated during prolonged machining, in the machined part. The requirements for inter-operational checks also increase.

Use of a mechanical spindle with separate drive reduces vibrations. By reducing the amplitude of vibration we can utilise the NC machine's dynamics, which is key for reduction of cycle time. The difference between the use of mechanical spindles on NC machine and a conventional machine is obvious in quality of the machined surface.
Another important point of the use of spindles is the reduction of vibrations, longer live of tools, as compared to conventional machines, on which the clamping is not as stable and the vibrations are higher, degrading the tool. The spindles, as compared to the clamping heads, have excellent high temperature stability and log life.

The use of mechanical spindles on NC machines, where the spindles can move in three or five operational axis, reduces the complexity of production and also the production time. On conventional machines it is possible to move the clamping head in three basic axis. Angular machining is demanding in terms of time, due to the adjustment of the tool or machined component. In complex cases it is necessary to make a fixture, which increases the production costs. [Sandvik 1997]

\section{NC MACHINE DESIGN FOR MACHINING SHAFTS.}

CNC machine is selected for multiaxis machining. Multifunctional turning mill, fitted with a control system, is selected due to the dimensions of the component. The machine will work in 5 axes.

The machine is fitted with a sloped bed, made from a single casting. The turning and milling spindles are driven through a gearbox, therefore achieving the required torque. The mechanical milling spindles and tilting heads are exceptional on such machines, but they provide substantial competitive advantages, power machining and long life. The machine is equipped with a counter spindle. The counter spindle has the same spindle and bearing dimensions as the left spindle housing, allowing the same machining performance on both spindles. This enables high-quality roughing. Both spindles have the same thermal properties because they use a similar construction and structure. When combined with a turret or other machining unit, the two main spindles can be operated in parallel. Another element for identical thermal properties is an improvement by small distances from the center of rotation to the bed base. The bed guide has a fixed chip configuration and other guides that allow minimal positioning distances between the chip trays to the lower guide bar. This type of milling spindles is the most important element of the machine.

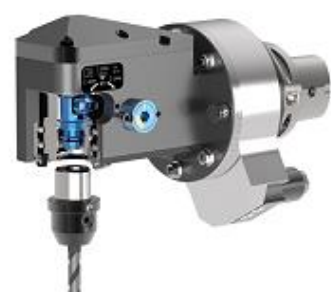

Figure 1. Tilting head

The top head of the machine is modified to allow clamping of technology aggregates during the automatic changes through unified and patented prismatic clamping. The machine works with one head in which the tool is clamped or can work with two heads with tools, both heads working simultaneously. Another advantage of the machine is the possibility of working movement. Three working movements are possible:

a) The rotary movement (working) is performed by the work piece; the tool has a static (fixed) position 
b) The rotary movement (working) is performed by the tool; the work piece has a static (fixed) position

c) The rotary movement is performed by both the tool and the work piece - this use is very advantageous especially in the form of (involute) surfaces where movement of the tool on the work piece is necessary The machine is fitted with special designed tool magazines. The magazines are easily accessible from the front and feature a stable and compact design. The pendulum tool drive with rack and pinion drive is equipped with linear axes to prevent centrifugal effects due to rotation. The superstructure solution of tool magazines can hold up to 200 tools. It is based on two chain magazines with 100 positions and a handling unit moves between them, passing tools to the spindle, along the entire machine.

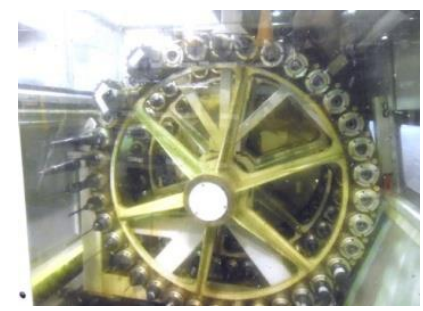

Figure 2. Integrated tool magazine

The machine can measure a range of values and send the values to the measuring centre. All digital measurements and scanning processes will take place directly on the machine and the results will be sent to the inspection database. Analogue measurements are especially useful for the assessment of surfaces or outlines, as well as for the inspection of the component's surface for machining faults.

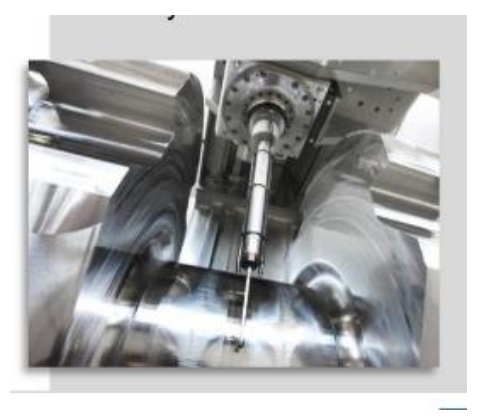

Figure 3. Measuring probe

\section{ANALYSIS OF THE CURRENT STATUS}

Shaft production is very costly. The production process includes many operations, which are not machining, but also inspection operations. The time intensity of the process is also increased due to the movement of the component from one workplace to another.

The decision regarding the purchase of a machine tool may be based on the overall perspective on the sequence of operations, not only for the product itself, but also from the perspective of the overall assembly of the product. If the shaft production is highly efficient, as compared to the production of individual assemblies, the quantity will be increased and the shaft will accumulate, waiting for the products. Such organisation of production is highly inefficient.

The main shaft of an electric motor was selected for the experiment in question. The shaft material is 16431 . The dimensions and weight of the shafts were determined based on the conventional machines used. Two shafts similar in shape but dimensionally different were selected. The first shaft has the largest pre-machining dimension in a width of $600 \mathrm{~mm}$, length $3,925 \mathrm{~mm}$ and weight $2,906 \mathrm{~kg}$, the second shaft has the largest premachining dimension in a width of $500 \mathrm{~mm}$, length 3,425 $\mathrm{mm}$ and weight $2,735 \mathrm{~kg}$.

Shafts of this size have been selected for their high machining demands. When manufacturing these shafts, it is necessary to adhere to the combination of basic machining requirements. These assumptions are technological conditions, rigidity and flexibility of the system.

The technological conditions include cutting parameters, tools and cutting fluids. The prerequisites for rigidity and flexibility of the system must be focused on the right choice of machine for the desired work piece. The machine must be rigid, rigid in relation to the weight of the work piece, but must also be flexible so that it can dissipate the resonances produced during machining. Provided we keep the preconditions, we get precise dimensions and a quality surface.

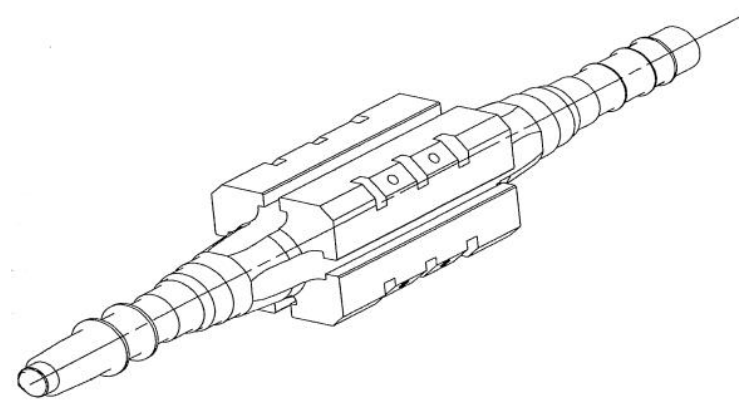

Figure 4. Experimental shaft

Conventional machines, which performed the monitored operations, were a centre lathe type SU $126 \mathrm{NC}$, manufactured by TOS Čelákovice, and a miller-borer type WD200A by Škoda Plzeň. The machine used for grinding is grinder BUC 63 A/4000 by TOS Čelákovice.

The same tools were used for machining on the conventional machine as well as the multi-functional centre. Turning tools by Valter were used for turning, milling cutters by Sandvik were used for milling, boring bars by Sandvik were used for boring and grinding discs by Tyrolit were used for grinding.

\section{EVALUATION OF THE EXPERIMENT}

Fig. 5 shows the assessment of the preparation time for individual machines. The turning machine and the millerborer require preparation time of 9.5 hours and the grinder 40 minutes. After integration of the preparation times on conventional machines the overall time is 19 
hours 40 minutes. The preparation time for the CNC machine is 1.5 hour.

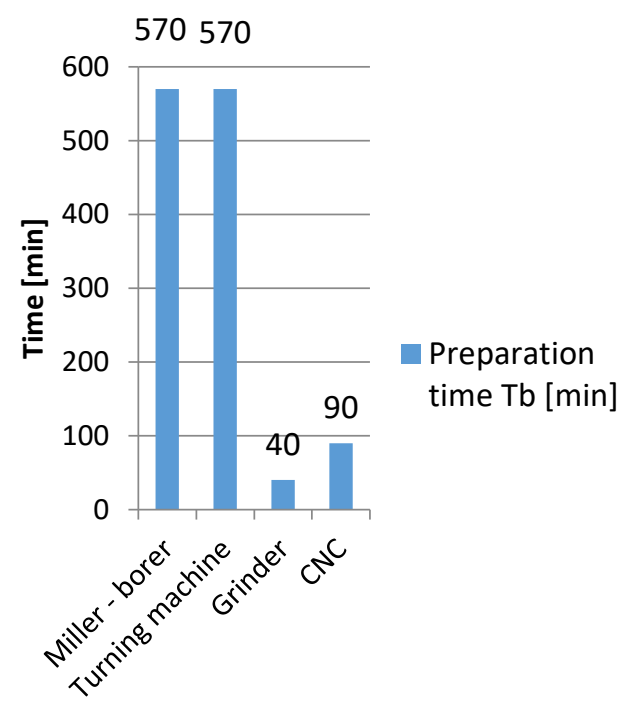

Types of machine tools

Figure 5. Chart of preparation times

Fig. 6 shows the assessment of the production time for individual machine tools. For the turning machine the production time is 73.75 hours, for miller-borer 111.5 hours and 1.5 for the grinder. After integration of the production times on conventional machines the overall time is 186.75 hours. The production time for the CNC machine is 182.75 hour.

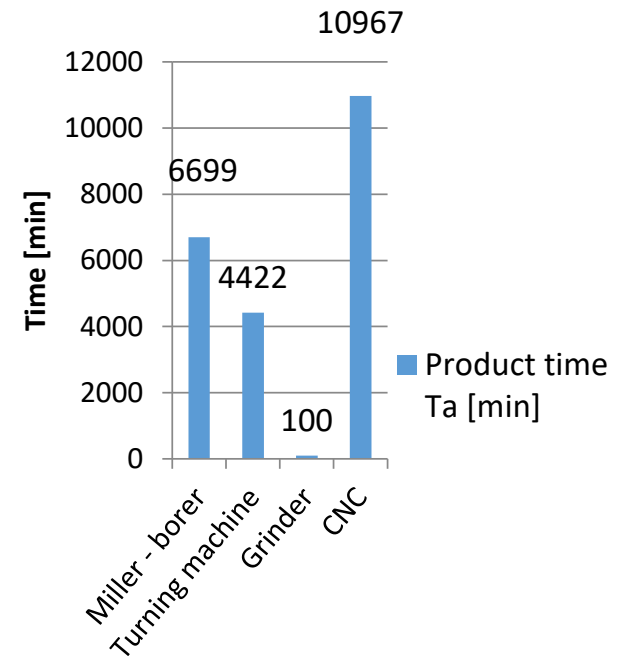

Types of machine tools

Figure 6. Chart of production times

Fig. 7 shows the assessment of the transport time for individual machine tools. For the turning machine the transport time is 1.75 hours, for miller-borer 1.5 hours and 12 minutes for the grinder, 3:5 hours in total. The transport time for the $\mathrm{CNC}$ machine is 50 minutes.

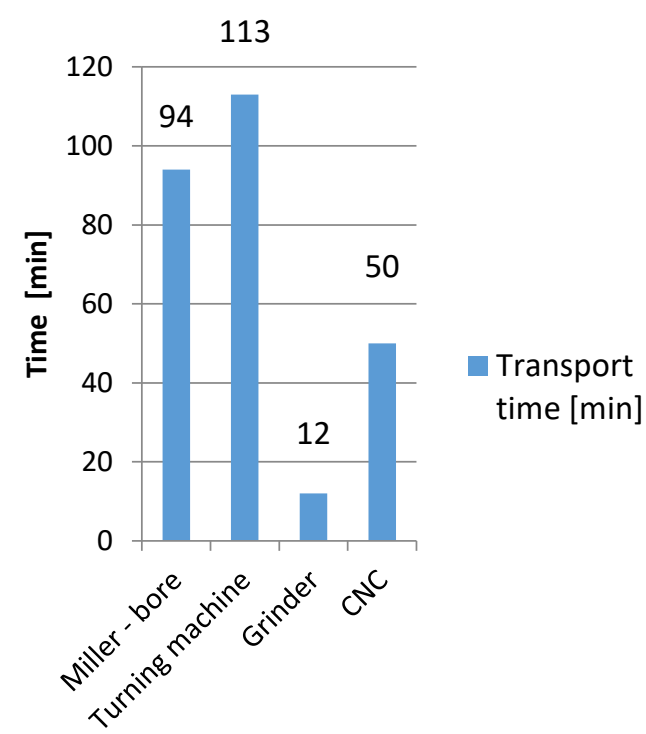

Types of machine tools

Figure 7 Chart of transport times

The average time of 30 minutes is calculated for a single inspection operation, in this case 120 minutes in total. It means a visual and dimensional inspection. During the production of shaft by this method on a multi-functional turning miller the time savings of 100 minutes will be achieved due to inspections directly on the machine, using a measuring probe.

The production of the shaft is very complex and demanding. It starts by squaring the ends and roughing the square parts. It is followed by roughing the cylindrical parts and the front bore. The following operation is milling the hammer groove, drilling all holes including threads, reaming and finishing central square parts to dimensions specified in the drawing. Subsequently all cylindrical diameters are machined to the specified dimensions, only ground diameters are left with an allowance. It is followed by grinding of tolerance ends and then the radial and front run-out are checked and indicated.

\section{ENGINEERING-ECONOMIC ASSESSMENT OF THE EXPERIMENT}

The costs of time of the selected shaft vary greatly in this experiment. The biggest difference is in the preparation time, where the result reaches app. 18 hours. We can add the transport time of 3 hours to this value. The overall time savings in the preparation and transport time is 21 hours. The savings are important, because the time doesn't add value and the production costs are reduced. Outside the aforementioned unproductive times, the number of shaft shafts increases due to the maximum utilization of the machine tool. In the production of conventional machines, it is necessary to exploit the production of three machines. The machines are obsolete, have higher overheads and use less quality tools. However, the timing is complex. Using a multifunction machine tool will significantly reduce production costs. These costs include electricity, tools, 
workers' pay, and downtime. Full utilization of the multifunction machine tool by the production of shafts will result in a financial return within 3 years.

\section{CONCLUSION}

The machining is one of the most frequently used methods of material removal. The increasing requirements on production technology of machining lead to the improvement and development of new machine tools. The machine allows us to use new technologies and tools. The result of such development is the combination of individual operations into one unit and the reduction of production times, making the production easier.

This contribution focuses on the combination of turning, milling, boring and grinding operations, which are performed on three machine tools, into one machining centre. The experiment was conducted on a selected shaft, which was machined by two technology procedures. The experiment with machining on three machine tools required a preparation of the shaft at the workplace before each operation and than a preparation of the workplace and the shaft for the operation at hand. This resulted in a large amount of non-production times and time-intensive planning of production of the component with high logistical demands. During the experiment, during which all operations were performed on one machine centre, the preparation and transport times were reduced as well as the associated administration (planning and logistics). The result is the overall time savings of 21 hours. The highest difference is 18 hours in preparation time, but also in transport time, in which the result is 3 hours. Another important and important difference is the reduction of production per machine, which leads to increased production efficiency and better planning. Consequently, to reduce overhead costs, downtime and wages of workers.

The multifunction machine was involved in an experiment of two selected shafts of similar shape. Its multifunctionality, however, allows to machine different types of shafts or other machine parts such as crankshafts, shafts for screw compressors, impellers for compressors, pumps etc. in one clamping. Due to the compatibility of the multifunction machine, the machining is dimensionally very precise and the requirements for surface quality are also met.

The reduction of prices of products puts great pressure on the production of individual components and the subsequent assembly. The reduction of times, which add no value, is very important, because it affects not only the price of the product, but also leads to increase of the efficiency of the production.

\section{REFERENCES}

[Bolek 1989] Bolek, A. Parts of machine, SNTL Praha, 1989 ISBN 80-03-00046-7

[Bilik 1994] Bilík,O. Machining II, VSB - TU Ostrava, 1994, ISBN 80-238-9694-6

[Brychta 2006] Brychta, J. Havrila, M. Zajac, J. Jurko, J. Trends in top machining, Zilina, 2006, ISBN 80-968954-27
[Kocman 2001] Kocman, K. Prokop, J. Machining technology, CERM Brno, 2001, ISBN 80-214-1996-2

[Sandvik 1997] Sandvik Coromant - Sandvik CZ.s.r.o. Machining Handbook - Book for Practitioners, Scientia Praha, 1997, ISBN 91-972299-4-6

\section{CONTACTS}

Ing. Ladislav Fuglicek

Technical university of Ostrava, Faculty of Mechanical Engineering

Department of Mechanical Technology

17 November 15/2172, 70833 Ostrava - Poruba, Czech Republic

e - mail: ladislav.fuglicek@vsb.cz 